\title{
Prospects for Peircean Epistemic Infinitism
}

\author{
Scott F. Aikin \\ Epistemic infinitism is the view that infinite series of inferential \\ relations are productive of epistemic justification. Peirce is explicitly \\ infinitist in his early work, namely his 1868 series of articles. Further, \\ Peirce's semiotic categories of firsts, seconds, and thirds favors a \\ mixed theory of justification. The conclusion is that Peirce was an \\ infinitist, and particularly, what I will term an impure infinitist. \\ However, the prospects for Peirce's infinitism depend entirely on the \\ prospects for Peirce's early semantics, which are not good. Peirce \\ himself revised the semantic theory later, and in so doing, it seems \\ also his epistemic infinitism.
}

1.

On the classical conception of knowledge, in order to know, you've got not only to believe something, what you believe has got to be true, and you've got to have a good reason as for why you believe it is true. But how do you know that's a good reason? It itself has not only got to be true, but you've got to have another reason for why you hold it is. And then for that reason, another. Then another. Then we're off to the races.

Virtually nobody thinks we should run that very long race. There is a variety of theories of how to shorten the distance. Foundationalism is the thesis that we may stop giving reasons with a special set of beliefs called basic beliefs. Coherentism is the thesis that at a certain level of reason-giving, we may stop when the beliefs in question have a special fit with the rest (or some set) of our beliefs. Contextualism is the thesis that we may stop with beliefs appropriate for the given circumstances. Externalism is a rejection of the requirement that subjects need to give or be aware of further reasons when they obtain.

Examples of philosophers and whole traditions abound for each of these theories of ways to leave off giving reasons, and it is easy to find many prime examples of and extended exchanges between these traditions. But it is difficult to find real examples of the tradition that we might call infinitist, those committed to the thesis that reasons may iterate infinitely. The old Pyrrhonean skeptical tradition has a version of accepting infinitism as a requirement on knowledge, but thereby they reject the project of knowing. This seems to be a 
plausible reading of the Agrippan modes and Sextus' use of them, but it is not a satisfying epistemological theory, since we are here looking for a theory of justification that dovetails with a theory of actual human knowledge. ${ }^{1}$ In passing, Peirce is mentioned as a candidate for holding the theory, but little more is said. Recently, Peter Klein (1999, 2000, and 2004) Jeremy Fantl (2003) and I (2005 and 2008) have argued for the view, and they have not only given accounts of the view's intelligibility but also its resistance to traditional arguments against it.

In light of these new developments in articulating and defending infinitism, I will retrieve the question as to whether Peirce was an epistemic infinitist. This is for two reasons. First, it is important that we have an adequate textual backing for these classifications, even if they are tentative and little hangs on them for current epistemological theorizing. We are scholars, and we should get it right. Second, in pursuing another example of a philosophical view, we might deepen and broaden our conception of it. Peirce's work is innovative in a number of areas, and it stands to reason that his views relevant to current issues in metaepistemology will be helpful.

I will argue for the following: First, that Peirce is explicitly infinitist in his early work, namely the 1868 series of articles, "Questions Concerning Certain Faculties Claimed for Man,” "Consequences of Four Incapacities,” and "The Grounds of Validity." Second, that Peirce's phenomenology of the relations between firsts, seconds, and thirds favors an interpretation of Peirce's infinitism as a mixed theory of justification, where infinite series of inferences are also supported by non-cognitive input from seconds. The conclusion, then, is that Peirce was an infinitist, and particularly, what I will term an impure infinitist. However, the prospects for Peirce's infinitism depend entirely on the prospects for his early semiotics, which are not good. Peirce himself revised the semiotic theory later, and in so doing, it seems also the motives for his epistemic infinitism.

\section{2.}

Broadly, epistemic infinitism is the view that infinite series of inferential relations are necessary for epistemic justification. The view may be construed as exceedingly demanding in that it may be an exclusivist thesis regarding sources of justification - namely that only these series are productive of justification. Such would be a pure infinitism, as is exemplary in Klein's 1999 and Fantl's 2003, where all the standing alternatives are shown insufficient against the backdrop of criteria for a sufficient theory of justification. ${ }^{3}$

The model for successful justification for pure infinitism is that of an infinite chain of justifying relations between commitments. However, infinitism may alternately be a mixed theory of justification, so that it is an ecumenical take on sources of justification. Mixed theories of justification are not exclusive with regard to what sources are allowable for epistemic justification, so, for 
example, Susan Haack's foundherentism makes room for both direct justification and justification from coherence (1993).

For impure infinitism, these series are productive of justification, but they are not the only sources, and they may work in tandem with other sources of justification. The model for infinitism on an impure theory would be an infinitely long chain of reasons supported by direct epistemic support at various nodes. Such support itself need not be infallible, and, in fact, precisely because of its fallibility, it must be supplemented by further reasons. Such would be an impure infinitism, as is exemplary in my own 2005 and 2008. The core of the infinitist view, however, is the same: the response to the regress problem is that of having reasons on to infinity.

An epistemic infinitism is at work in Peirce's famous 1868 Journal of Speculative Philosophy series "Questions Concerning Certain Faculties Claimed For Man" and "Consequences of Four Incapacities." Peirce's main purpose is to show that all cognitions are inferential, not immediate or intuitional. At first, Peirce seems sympathetic to the issues motivating the foundationalist-intuitionist program in the regress problem. Question 7 of the "Questions" essay is whether there are any cognitions not determined by previous cognitions. In short, are there intuitions? Peirce notes that:

It would seem that there is or has been; for since we are in possession of cognitions, which are all determined by previous ones and these by cognitions earlier still, there must have been a first in this series or else our state of cognition at anytime is completely determined according to logical laws, by our state at a previous time (CP 5.259).

But he then notes:

But there are many facts against this last supposition.... [It] is impossible to know intuitively that a given cognition is not determined by a previous one, the only way in which this can be known is by hypothetic inference from observed facts (CP 5.260 emphasis in the original).

The Peircean definition of intuitions on the semiotic theory is that they are signs that refer immediately to their objects. The epistemic corollary is that an intuition is a "premiss not itself a conclusion" (5.213).

The question of determination of one thought by another, though, complicates the matter, since these determinations may be semiotic, epistemic, or merely causal in nature. I will take it here that so long as Peirce's arguments are that these semiotic determinations are interpretive, they are jointly causal and epistemic. Call this the dual role of semiotic interpretation: the reasons one has for an interpretation are both explanations for how one arrived at an interpretation and justifications for that interpretation. 
Peirce further refines his notion of an intuition such that intuitions are (i) first cognitions determinable by logical laws (5.259), (ii) premises not themselves conclusions (5.213), and (iii) something about which it can be a question as to whether they are intuitions, even if one has them (5.260). Peirce synthesized the semiotic features of such judgments (their inferential role as antecedents to chains of further inferences) with their epistemic features (the justification one has in having them and the justification they confer through inference). So the question of the regress problem is whether there can be immediate reference to something that both gives a cognition its content and its epistemic status as an immediately justified belief.

Peirce's requirement for immediate reference is that if reference is immediate, it must be immediate that it is immediate. That is, we must intuitively know when we have intuitions. Let us call this the meta-requirement. So the difference between intuitive and non-intuitive knowledge itself must be intuitive. ${ }^{4}$ Peirce frames the argument for the requirement as such:

[I]t is plainly one thing to have an intuition and another to know intuitively that it is an intuition, and the question is whether these two things, distinguishable in thought, are, in fact, invariably connected, so that we can always intuitively distinguish between an intuition and a cognition determined by another.(5.214)

Peirce, then, from his conception of cognition, derives the following argument that intuitions and their immediate knowability as intuitions are connected:

[A]ll the cognitive faculties we know of are relative, and consequently their products are relations. But a cognition of a relation is determined by previous cognitions. No cognition not determined by a previous cognition can be known. It (intuition) does not exist, then, first, because it is absolutely incognizable, and second, because cognition exists so far as it is known. (5.262)

Peirce's first case is that, given that there has been (up to Peirce's time and up to now, too) debate about what is intuitive knowledge and not (the rationalismempiricism debate, the current arguments against consciousness), it seems clear, on the meta-requirement, that such intuitions do not obtain. Additionally, given the meta-requirement, for the second-order-intuition to be intuitive, we would need a third intuition, and a fourth for that. As a consequence, it would be unclear how intuitions could solve the regress problem at all, since their introduction yields a new meta-regress. ${ }^{5}$

Clearly, Peirce's argument here depends crucially on the metarequirement for intuitions. We get an extended argument for the metarequirement and the conception of cognition behind it in the 1868 sequel to the "Questions” paper, “Some Consequences of Four Incapacities.” The thesis of the 
paper is that all mental events are results of the manipulation of signs. Thoughts are combinational; they, to be thoughts at all, must be well-formed-formulae, and the model for the movements of thought must be that of valid inference (CP 6.338).

The components of these formulae are signs: feelings, images, emotions, representations. For these thoughts to have content and for them to be of something, they must not only be well-formed, but they must be meant (CP 5.289). How thoughts have intentionality, on this account, is that the signs comprising thought have objects because they are interpreted as being of something by other signs. Without the interpretant, the original sign loses its meaning. It is therefore essential that signs come not just as sets of well-formed formulae, but as sets that mean by their interrelations. So thoughts, as combinatorial, are like sentences, and sentences do not mean anything unless they are read and interpreted.

So it goes for thought. The rationale for the meta-requirement, then, is that the condition for a cognition to exist as a cognition is for it to be known to exist as such (CP 5.262). As long as there is a problem with nailing down whether or not there are intuitions, they are not known to exist. So they don't. Pierce anticipates a familiar regress of analysis problem (an analogue of the epistemic regress) in light of this requirement. If we cannot have thoughts without signs, then it seems for all interpretations, there must be interpretations of them, and then interpretations of them, and we're off to the races, but this time on a semantic or semiotic level.

Yet Peirce accepts infinitism on this level also, as he notes that the alternative requires that there be intuitions that play non-derived inferential roles. To hold that there must be such notions "assumes the impossibility of an infinite series. But Achilles, as a fact, will overtake the tortoise. How this happens, is a question not necessary to be answered at present, as long as it certainly does happen” (CP 5.250, emphasis in original). So Peirce is not only committed to there being a requirement of infinite analysis, he is committed to the thesis that these infinite analyses are actual. Just as Achilles actually catches the tortoise, and in so doing traverses an infinity of spaces, we mean and reasonably believe, and in so doing, are involved in an infinity of interpretations and justifications. The question, despite the fact that Peirce tables it, is how exactly this is brought to actuality.

Let us take Peirce's analogy with the Achilles case more seriously. One of the principles behind the paradox is that Achilles cannot make an infinite number of journeys in finite time. But the question with this requirement is why not. As the distances become shorter and shorter between Achilles and the Tortoise, the time it takes for Achilles to traverse the distance grows progressively shorter. As such, the times, instead of stretching out to infinity, contract to the limit of Achilles overtaking the tortoise. Time, however, does not start and stop with each journey. Neither does Achilles. The question is whether 
thoughts have the same underlying continuity that time and Achilles' movement have. On Peirce's model, they do.

Peirce's phenomenology provides an account of the continuity of thought in interpretation. The levels of sign-interpretation are triadic. First, are emotional, atomic, interpretants; second, energetic interpretants; and, third, are logical interpretants (CP 5.475). The triadic scheme classifies any object of thought, and presumably, thoughts themselves (as they may be objects of thought, too). For our purposes, the most useful version of the view is rendered in terms of the logic of relations, where the relata stand in one of three kinds of irreducible relations: monadic, dyadic, and triadic. For example, some x's redness is monadic, some $\mathrm{x}$ bumping into some $\mathrm{y}$ is dyadic, and some A giving some $\mathrm{z}$ to $\mathrm{B}$ is triadic. ${ }^{6}$

Firsts are simple monadic elements, immediate qualities of feeling, noncomparative properties. Seconds are actions and reactions, causes and effects, the brute force of resistance. As Peirce describes secondness it is that "which the rough and tumble of life renders most familiarity prominent. We are continually bumping up against hard fact" (CP 1.324). Thirds are lawlike mediated relations. Signs and significant behavior are clearly the best candidates, for their status requires the relations of who-the-sign-is-for, what-the-sign-is-of, and the sign itself. Thoughts themselves, again on the semiotic theory, are thirds, as they have their combinatorial elements, but they are interpretations of other thoughts and experiences, and for them to mean, they must be interpreted.

Firsts, as feelings, are the primary constituents of consciousness - they are the data that give rise to empirical judgments. They, however, do not function as sense-data or immediate objects of awareness. Rather, they are the raw fluid material of awareness. Because they are prior to interpretations, we are (on Peirce's theory) not aware of firsts as such. We come to awareness of them as discrete seconds - the fact of some quality bearing on us, the world bumping back, the resistance of things to our will. Facts impose themselves on us in experience, and that pressing is announced with the presence of sensory properties. But for us to recognize those facts as such, to understand and make inferences on the basis of our experiences, they must be taken as being distinct law-like events indicative of their correlate facts (CP 1.420). As such, thirdness of thought is the abduction of understanding of what is happening in the world on the basis of the secondness of experience. Returning to the analogy with Achilles and the tortoise, the distinct movements of thought with thirds depends on the fluid movements of awareness in firsts. The continuity of consciousness in firstness, however, is the ground for thirds. To see the situation as paradoxical is to take thirds to be the antecedent elements.

Most certainly thirdness is our primary object of interest for epistemology, and Peirce's argument against intuitionism is clearly made on the level of thirds. It is only when thoughts are interpreted on this level that they may bear inferential relations with each other and are candidates for the metarequirement. However, these relations between thirds are not the only 
epistemically relevant relations. And though firsts solve the problem of the continuum, there is a final category that plays an epistemic role.

Secondness has a place in the Peircean epistemic program, especially if we are considering the possible place of non-inferential justification for intuitions. If an intuition is a thought that immediately refers to its object, instead of looking at the mediacy of reference on the theory of signs, the possibility of direct reference may be found in the ontology of the signs themselves.

The place of seconds in the semiotics is the requirement that for thought to have the determinant logical content it must have to be the kind of thoughts capable of us in a position where we can have knowledge: something must exist, there must be something that can be knocked up against, and therefore something in consciousness that cannot be thought away. There must be something that forces our determinate acknowledgement (CP 2.358). The place of secondness in our interpretive triads is that it is a condition not just for the being of the objects of our thought, it is a condition for the existence of the thoughts themselves:

For as long as things do not act upon one another, there is no sense or meaning saying that they have no being, unless it be that they are such in themselves that they may perhaps come into relation with others (CP 1.25)

Guy Debrock $(1997,27)$ has termed this requirement "the Peircean ontological principle": if there is no secondness, there is nothing at all. Thirdness, as habits of thought requires that there be occurrences causally suitable to form those habits.

Consequently, thoughts about the seconds that give rise to them are themselves referentially direct. A person may say, "I am being appeared to thusly" or "He said that the car wouldn't look like that," or "Oh, this is how it feels to win the race." ${ }^{7}$ In making such references, the speakers must be both aware of the objects of reference and capable of articulating what such references entail. But the awareness of what they are experiencing is not provided by their awareness of the context or inferential and practical commitments or consequences. They are aware of the causal connection between the experiences and their actions. One takes aspirin because headaches hurt, not vice versa. These seconds, the pressure of the headache, and its correlate effects in our behavior and our beliefs, have a force that we feel and articulate with assent to proper descriptions of them. Most certainly there is another interpretive element to bringing this force to full belief, but the interpretation depends on the material component of the sign for its impetus (CP 5.292).

So there is a component of thought, on the Peircean theory, wherein there must be non-doxastic support for beliefs. Seconds in experience impel us to 
formulate commitments. These formulations themselves, on what I'd termed the dual role of semiotic interpretation, with causal and epistemic reasons functioning in tandem, require further inferences, but the impetus itself is not inferential. It is the condition for inference. ${ }^{8}$

Peirce’s argument from “Questions” depends on a robust requirement for intuition: namely, that the intuition provides justification that itself is perspicuous to the subject that has it, and further, that the subject's justificatory status for her beliefs must not only be available to the subject's reflection, but it must be a constitutive component of the belief. From this thought, Peirce derives the meta-requirement. The mistake interpretively is to take the requirement unqualifiedly to entail the justification assessment must obtain for all intuitive or direct epistemic support. Direct support may come in a variety of forms, and Peirce's own semiotic is posited on requiring that some non-inferential support function at the heart of the interpretive enterprise. The conception of the progress of inquiry itself requires some feature of non-inferential, defeasible support:

Besides positive science can only rest on experience; and experience can never rest on absolute certainty, exactitude, necessity, or universality (CP 1.55).

And in the 1903 Harvard lectures, Peirce is clearly committed to the thesis that "perceptual judgments are the first premises of all our reasonings" (5.116), and that "all our knowledge rests on perceptual judgments" (5.142). Peirce was (at least by 1903) committed to there being asymmetric and non-doxastic support, but he denied that the criteria for such a role was to be the restricted categories arising from the project of refuting skepticism. It does require that if there is knowledge, there is non-inferential support.

However, it seems clear that the argument from the meta-requirement in "Questions" and "Consequences" is still in play. Beliefs bearing this indexical relation to the seconds from which they arise must still have further beliefs mediating their inferential relations with other beliefs. Sensations so far as they represent something are determinate according to a logical law by previous cognitions (CP 5.291). That we have such and such an experiential event may be provided by the index, but what the sensation is of must be provided by the event's relation to other beliefs. We can have direct non-inferential access to our experiences as seconds, but for us to know what those experiences are of as thirds requires a measure of interpretation.

We have, then, a model for why Peirce would say that there are no intuitions in the sense of first thoughts, ones that do not depend on others for their content or justificatory status - for the thoughts to be thoughts, they must play be the consequence of inferences. The requirements for justification, further, are that premises may function as premises only if they themselves are conclusions of further arguments. 
However, this does not preclude the direct support provided by indexicals in experience. In fact, without the secondness of these indexicals, the arguments themselves could never be formulated. We make, as Peirce frames the alternative to intuitions, "hypothetic inferences from observed facts" (CP 5.260) This is not to say that this support is indefeasible. In fact, quite to the contrary the inferences are hypothetic. The support provided by direct justification is foundationalist in one way and non-foundationalist in another. In the way it is foundationalist, the direct support provided by seconds are brute and give rise to the content of interpretants. The support is non-foundationalist in that these events enter into consciousness and play the roles they do because they are interpreted and the consequences of related inference. Seconds cause us to believe things spontaneously, but we arrive at their content by interpretation the beliefs are direct in one way, but indirect in another.

Peirce's early theory of justification, then, is committed to two seemingly inconsistent theses. On the one hand, there must be an inferential or interpretive feature to all epistemic support. ${ }^{10}$ This drives Peirce's epistemology in the direction of infinitism. On the other hand, there can, and it seems must, be a non-doxastic support for premises for them to even exist and be justified at all. This drives Peirce's epistemology back in an empiricist-foundationalist direction. The result is the seeming contradiction of on the one hand requiring that all justificatory support be inferential but on the other hand allowing seconds to justify.

This contradiction, though, arises only if one takes the theories of sources of epistemic justification in tension here to be exclusivist - namely, that if one allows in foundationalism or infinitism, one cannot allow in the other. But impure theories are non-exclusivist, and it seems that Peirce is working with a mixed theory of justification. Seconds may play a role in a series of reasons, but on the requirement that they do so in combination of a series of interpretations that give seconds epistemic-semiotic significance. By this, our series of inferences may also be held accountable to our experience, so that there are observational judgments justified by the contents of the experience. One has the experiences, and with them, one is justified in having beliefs depending on those correlate experiences. But these experiential beliefs do not play a singular role in cognitive life, as their relation to other beliefs is mediated by other beliefs. For a subject's belief that she is being appeared to like this to be relevant to her other beliefs, the appearance must be interpreted as a representation of something, or that it is a symptom of being in some situation that gives rise to certain representations.

Given that all inferential justification is mediated by interpretation, no indexical belief about one's experience (that one is experiencing this) is ever sufficient by itself for the justification of another belief, but it may play a role in the determination of the other belief's status (especially if that other belief entails that one instead be experiencing that). However, whether or not one has 
that experience does not depend on other interpretations or inferences, but only on the brute fact of experience.

Peirce explicitly rejects the notion that the regress argument shows that there must be a first cognition. His arguments in the 1868 series are precisely designed to show that there are not first cognitions, because inference is necessary for any cognitive element of life to have semantic or epistemic value.

However, Peirce also takes himself to have shown how it is possible for these series to begin, given this requirement. Peirce shows that cognition arises by a process of "unfolding" (CP 5.263) in which the non-inferential material features of signs are the explanatory, and eventually justificatory, features for cognitions. He notes in the third paper of the 1868 series, "The Ground of Validity”:

[I]t does not follow that because there has been no first in a series (of premises), therefore that series had no beginning... for the series may be continuous, and may have begun gradually... (CP 5.327).

This is to say that the continuity of thought arises less like the beginning of a song with a first note, but more like someone progressively turning up the volume, and the song fades in. If there were a first thought, it could neither have content nor normative status, on the Peircean semiotic. However, thought does arise for individuals, and it seems to come about gradually as a whole. Again, this is because of the requirements of the semiotic here with the metarequirement for first thoughts and the ties between a cognition's content and its epistemic status. The dual role of semiotic interpretation as both causally determinative and epistemically justificatory is the locus of this connection. For a thought to mean, it must be interpreted. Some interpretations are better than others by their responsiveness to the signs and their syntax, and as such, some are justified or not. Interpretations have both semiotic-semantic and epistemic roles to play.

One question is which role is conceptually prior. Would Peirce, say, be a semiotic infinitist independently of his epistemic infinitism, or vice versa? One thought regularly expressed among contemporary epistemologists is that epistemological theories cannot be articulated independently of a theory of meaning. If we are interested in inferential justification, then some notion of the meaning of the variables between the logical functions must be implicated. Inference is a semantic notion. A justified inference, then, is a conceptually dependent notion - we've got to get our semantics nailed down to do epistemology properly.

Peirce's project is structurally similar - it is Peirce's semiotic commitment that thought must be understood as inferential that yields (a) the meta-requirement for intuitions, (b) the intelligibility of a regress of interpretations, and (c) the demonstrative relation between thoughts and the 
seconds that give rise to them. Peircean infinitist epistemology rides piggyback to Peircean infinitist semiotics.

3.

The problem is that Peirce's 1868 semiotics were flawed on three fronts. First, Peirce's theory of indexicals was inadequate to the task. Or, at least, Peirce later thought so. All the demonstrative indexes are limited to seconds and thirds in consciousness. This leaves Peirce's semantics incapable of analyzing reference to objects in the world.

Peirce's case for demonstratives in "Consequences" is that they bear a "real physical connection of a sign with its object, either immediately or by its connection with another sign" (CP 5.287). The question, then, is how these connections are established. On Peirce's semantics, it could only occur as a static system of relations between judgments. That is, if intuitions have the metarequirement, then demonstratives do too. As a consequence, on the 1868 Peircean model, there is no escape from the circle of judgments. ${ }^{11}$ Peirce must have realized this problem, as "Fixation" in 1877 has it such that "external objects affect our senses according to regular laws, and that we may, on the basis of this knowledge, come to know them." (CP 5.384). The mediacy of judgments and interpretations of knowledge of things other than judgments had been dropped for a causal theory of reference. ${ }^{12}$ Given that Peirce embraced infinitism on the basis of the requirement for interpretive mediacy for reference, his later acceptance of such reference seems to withdraw motivation from taking the view on. Peirce still could have been an infinitist in the 1877-78 papers ("Fixation" and "How to Make our Ideas Clear") and later, but he had no positive reason to be so.

Second, Peirce would also have had to explain how demonstrative reference to seconds provides epistemic support. Insofar as Peirce's requirements for support run that only inference can provide support, it seems that Peirce's theory may suffer from a familiar dilemma: either the demonstrative reference is cognitive or it isn't. If it is cognitive, then it must be so because it has been interpreted. If so, then it cannot provide epistemic justification (since that status is possible only if it is conferred by a further cognitive state). If the reference is not cognitive, then it cannot provide support, because it cannot function in inference. ${ }^{13}$

So long as Peirce is committed to the requirement that inference is the sole means of support, then it is still unclear how seconds may justify any other state. They may cause them (which is how they arise), but without the inferential-interpretive component, they cannot, on Peirce's requirements, play an epistemic role. This, again, is a consequence of what I earlier termed the dual role of semiotic interpretation as both causally determinative of content and epistemically justifying. It seems with seconds, we have a question as to how the epistemic element arises without further inferences. 
The third problem is that it is unclear how Peirce's account of interpretation in the 1868 essays has anything to do with truth. We know that signs, in order to mean, must be interpreted by other signs. But we have no criteria for what a correct or incorrect interpretation is. Peirce must be committed to this difference, as it is crucial to save his theory that all thought is modeled on valid inference (CP 6.338). He explains cases of fallacious reasoning as cases where one misinterprets or confuses a rule of inference, and thereby uses the wrong one (CP 5.282).

But what is this notion of misinterpretation? On the semiotic theory, inferences and content of the thoughts they move from are established by other inferences. How, then, could they be distinct from the wrong ones, since $e x$ hypothesi they are both logically determinate enough to be cognitively significant? If it is a brute fact of the matter which is right, then there are components of consciousness that have their cognitive contents independently of interpretation. The theory of seconds earlier is supposed to explain how interpretations come about, but it is silent on whether those interpretations are correct or incorrect. Consequently, if the 1868 theory is to be salvable, a more robust theory of seconds is necessary.

A closing question is whether another Peircean epistemic infinitism could be abstracted from the model for inquiry and truth that is incipient in the 1868 articles:

[T] he real ... consists of those which, at a time sufficiently future, the community will always continue to re-affirm (CP 5.312).

And the theory runs through the later work (1901):

Truth is that accordance of the abstract statement with the ideal limit towards which endless investigation would tend to bring scientific beliefs (CP 5.565).

The problem for such a model for the purposes of epistemic infinitism is that it underdetermines the theory of justification necessary for the task. Let us take the theory of reality and truth here on an ideal convergence model of infinitely extended investigation. This is admittedly a contentious interpretation. However, if we do not take the model as requiring infinite investigation, there is clearly no tie to epistemic infinitism. The question is whether epistemic infinitism can be tied to the theory of truth as interpreted as requiring infinite inquiry. If the theory of truth articulated here is not a convergence theory, then it will not support an infinitist epistemology. That seems clear. However, if the convergence theory of truth is right, the question is what follows for Peirce's epistemology?

On the model of ideal convergence of infinite inquiry, does epistemic infinitism follow? The answer is that endless investigation does not mean 
infinite series of justifying inferences. Endless investigation of a proposition's truth, at any time, may change which other propositions are in the series, change their order, or add new inferences. Or it may reveal that the series does not provide the requisite support for p by defeating some branch necessary for p's justification. Or it may add new nodes to the series infinitely, so that the series may stretch to infinity. But there is nothing to the notion of infinitely extended inquiry that means that the series of justificatory inferences it yields are infinite or otherwise.

Endless inquiry, I believe, is reflective of the fallibilist component of Peirce's epistemology and its requirement of revisability. The notion of truth at the end of endless inquiry is more a model for an ethic of well-regulated inquiry than a model for epistemic justification, infinitist or not. We may be justified now, but that does not make our beliefs immune to correction when new information comes in. We may be open to infinite iterations of correction and revision, but such a structure itself does not require that the supporting reasons be infinite. In this respect, Peirce's later theory of inquiry may be called epistemically infinitist, because his epistemology does not rule out the possibility of infinitely extended chains of inferences, but such an infinitism (as opposed to his views in 1868) is hardly explicit enough to merit little more than a qualified attribution of the view. The later view is, on what's given, consistent with infinitism, but hardly an endorsement.

Peirce was an infinitist in his early work, namely in the 1868 series of articles in The Journal of Speculative Philosophy. I've argued that the infinitism may be understood on what I've termed impure infinitism. However, Peirce's infinitism was held on the basis of a flawed semiotic theory. Peirce himself later recognized these defects, and in correcting them, it seems he also took leave of the epistemic view. In any case, he no longer felt it necessary to explicitly endorse it.

\section{ACKNOWLEDGMENTS}

Thanks to Caleb Clanton, Allen Coates, Charlie Hobbs, Cornelis de Waal, Michael Hodges, John Lachs, Joseph Margolis, Brian Ribeiro, Andrew Sergienko, Aaron Simmons, and Robert Talisse for their many helpful comments on and discussions regarding this paper.

\section{NOTES}

1. Peter Klein makes a case for this reading of Sextus in 2004. See Sextus' use of the regress horn of the Agrippan modes (PH I.168).

2. References to Peirce's Collected Works will be designated: (CP, Volume \#, p\#). 
3. Klein and Fantl use different criteria for their arguments. Klein's requirements are those of non-arbitrariness and non-circularity (1999, 222), and Fantl's are intelligibility of complete and degreed justification $(2003,538)$.

4. See Davis $(1972,8)$ for an account of the meta-requirement. Note, also, that this requirement is analogous to the Pyrrhonean requirement for regress-ending hypotheses (PH 164-177) and also has found other forms in BonJour's metajustifications argument (1985, 30-33), and have figured widely in response to foundationalism. See Oakley (1976, 222-223), Possin and Timmons (1989, 206) and Klein (1999, 277-279).

5. It seems though, that if Peirce is willing to accept the first order level with the regress, then why should a regress of intuitions be objectionable at the second order? Couldn't it be intuitive that it is intuitive that ... that it is intuitive that p? So long as intuition functions, for those who have them, as transparent (i.e., that one simply grasps the content, not the embedding), such embeddings would not be an issue.

6. See Cheryl Misak's discussion of Peirce's categories (2004, 22). (CP 5.296)

7. See Peirce's discussion of pure demonstrative applications of thought-signs

8. Cf. Delaney (1993, 89 and 111-118) who takes this point as indicative of a weak foundationalism in Peirce's early works.

9. This strategy is noted by Floridi $(1997,54)$, who extends Perice's response to skeptics as an argument for convergent realism.

10. See CP 5.318 for Perice's explicit endorsement of this thesis.

11. See Thompson $(1978,79)$ and de Waal $(1996,436)$ for versions of this problem for Peirce's early semantics.

12. Hookway (2002, 18 and 29-30) notes this difference and attributes Peirce's change of mind to Royce's influence. See also Short (2004) for an account of the development of Peirce's semiotics and theory of indexes.

13. Versions of this familiar dilemma can be found in Sellars (1963, 146-147), Davidson (1986, 311), Rorty (1979, 95-96), and BonJour (1985, 69)

\section{REFERENCES}

Aikin, Scott F. 2005. “Who’s Afraid of Epistemology’s Regress Problem?” Philosophical Studies 126: 191-217.

Aikin, Scott F. 2008. "Meta-epistemology and the Varieties of Epistemic Infinitism." Synthese 163.2 (July): 175-185.

BonJour, Laurence. 1985. The Structure of Empirical Knowledge. Cambridge, MA: Harvard University Press.

BonJour, Laurence. 2003. Epistemic Justification: Internalism vs. Externalism, Foundations vs. Virtues. Malden, MA: Blackwell.

Chisholm, Roderick. 1977. Theory of Knowledge, 2nd edn. Englewood Cliffs, N.J.: Prentice Hall. 
Clark, Romane. 1988. "Vicious Infinite Regress Arguments.” Philosophical Perspectives 2: Epistemology 1988: 369-380.

Cling, Andrew. 2004. “The Trouble with Infinitism.” Synthese 138.1 (January): 101-123.

Cornman, James. 1977. "Foundational versus Non-foundational Theories of Empirical Justification.” American Philosophical Quarterly 14: 287-297.

Cortens, Andrew. 2002. "Foundationalism and the Regress Argument.” Disputatio 12: 22-36.

Davidson, Donald. 1986. “A Coherence Theory of Truth and Knowledge,” in Truth and Interpretation, ed. Ernest Leplore (New York: Blackwell), pp. 307-319.

Davis, William H. 1972. Peirce’s Epistemology. The Hague: Martinus Nijhoff.

Debrock, Guy. 1997. "Perice’s Category of Secondness and Information," in C. S. Peirce: Categories to Constantinople, ed. Jaap van Brakel and Michael van Heerden (Belgium: Leuven University Press), pp. 31-46.

Deutscher, Max. 1973. “Regresses, Reasons, and Grounds.” Australasian Journal of Philosophy 51: 1-16.

Delaney, C. F. 1993. Science, Knowledge, and Mind: A Study in the Philosophy of C.S. Peirce. South Bend, Ind.: Notre Dame University Press.

De Waal, Cornelis. 1996. "The Real Issue between Nominalism and Realism, Peirce and Berkeley Reconsidered.” Transactions of the Charles S. Peirce Society 32: 425-441.

Fantl, Jeffrey. 2003. “Modest Infinitism.” Canadian Journal of Philosophy 33: 537-562.

Floridi, Luciano. 1997. "The Importance of Being Earnest: Skepticism and the Limits of Fallibilism in Peirce,” in C.S. Peirce: Categories to Constantinople, ed. Jaap van Brakel and Michael van Heerden (Belgium: Leuven University Press), pp. 47-60.

Foley, Richard. 1978. "Inferential Justification and the Infinite Regress." American Philosophical Quarterly 15: 311-316.

Haack, Susan. 1993. Evidence and Inquiry. Malden, MA: Blackwell.

Hookway, Christopher. 2002. Truth, Rationality, and Pragmatism: Themes from Peirce. New York: Oxford University Press.

Klein, Peter. 1999. "Human Knowledge and the Infinite Regress of Reasons." Philosophical Perspectives 13: Epistemology 1999: 297-325.

Klein, Peter. 2000. "Why not Infinitism?" in Proceedings of the Twentieth World Congress of Philosophy, Vol. 5, ed. Richard Cobb-Stevens (Bowling Green, Ohio: Philosophy Documentation Center), pp. 199-208. 
Klein, Peter. 2004. “There is no Good Reason to be an Academic Skeptic,” in Essential Knowledge, ed. Steven Luper (New York: Pearson-Longman), pp. 299-309.

McGrew, Timothy. 1995. The Foundations of Knowledge. Lanham, Md.: Littlefield Adams.

Misak, Cheryl. 2004. “Charles Sanders Peirce,” in The Cambridge Companion to Peirce, ed. Cheryl Misak (Cambridge, UK: Cambridge University Press).

Moser, Paul. 1985. “Whither Infinite Regresses of Justification?” Southern Journal of Philosophy 23: 65-74.

Oakley, I. T. 1976. “An Argument for Scepticism Concerning Justified Belief.” American Philosophical Quarterly 13: 221-228.

Peirce, Charles Sanders. 1931-1958. Collected Papers of C. S. Peirce, 8 vols., ed. Charles Hartshorne, Paul Weiss, and Arthur Burks (Cambridge, MA: Harvard University Press).

Pollock, John. 1974. Knowledge and Justification. Princeton, N.J.: Princeton University Press.

Possin, Kevin and Mark Timmons. 1989. "What's Wrong with Paul Moser's Intuitionistic Foundationalism.” Philosophical Studies 56: 199-208.

Post, John. 1980. "Infinite Regresses of Justification and Explanation.” Philosophical Studies 38: 32-50.

Post, John. 1987. Faces of Existence: An Essay in Nonreductive Metaphysics. Ithaca, N.Y.: Cornell University Press.

Rorty, Richard. 1979. Philosophy and the Mirror of Nature. Princeton, N.J.: Princeton University Press.

Sellars, Wilfrid. 1963. Science, Perception, and Reality. New York: Humanities Press.

Sextus Empiricus. Outlines of Pyrrhonism. (PH)

Short. Thomas L. 2004. "Peirce's Theory of Signs," in The Cambridge Companion to Peirce, ed. Cheryl Misak (Cambridge, UK: Cambridge University Press).

Sosa, Ernest. 1974. “How Do You Know?” American Philosophical Quarterly 11: 113122.

Thompson, Manley. 1978. “Peirce’s Verificationist Realism.” Review of Metaphysics 32: 74-98. 
Scott F. Aikin

Lecturer in Philosophy

111 Furman Hall

Vanderbilt University

Nashville, TN 37240

United States 